\title{
Bottom-up control regulates patterns of fish connectivity and assemblage structure in coastal wetlands
}

\author{
Ben Davis*, Carlo Mattone, Marcus Sheaves \\ Centre for Tropical Water \& Aquatic Ecosystem Research, Estuary \& Tidal Wetland Ecosystems Research Group, \\ School of Marine \& Tropical Biology, James Cook University, Townsville, Queensland 4811, Australia
}

\begin{abstract}
We examined the potential for patterns in invertebrate prey distribution to act as a key driver of fish distribution across a coastal wetland system. Seascape and metacommunity approaches recognise that faunal assemblages in coastal and freshwater systems are structured by responses to multi-scale connectivity and local environmental conditions. However, we currently have a poor understanding of how different groups of aquatic organisms affect each other's distribution. Most fish in freshwater and coastal wetland systems feed predominantly on benthic invertebrates and zooplankton. To investigate the extent to which these invertebrate taxa exert control over fish distribution, we sampled fish, benthic invertebrate and zooplankton assemblages across 13 inter-connected pools on a salt-marsh in North Queensland, Australia. We found strong and inter-annually consistent spatial concordances among the 3 faunal components, characterised by higher densities of benthic invertebrates and zooplankton in pools at lower elevations on the salt-marsh — reflected by high densities of planktivorous and benthivorous fish, and lower densities of benthic invertebrates and zooplankton in pools at higher elevations - reflected by dominance of fish species trophically de-coupled from these taxa (detritivores, insectivores, and herbivores). Further supporting the idea of trophic linkages, the 2 most invertebrate-rich pools also harboured the greatest densities of benthivorous and zooplanktivorous fish, which in turn attracted the wetland piscivores Lates calcarifer and Megalops cyprinoides. This is indicative of bottom-up forcing acting across 3 trophic levels, a process that is likely facilitated by the frequent tidal connections among pools, which allows for regular redistribution of fish. Prey availability should be considered as a key component of the spatial ecology processes that shape fish assemblages across coastal and freshwater wetland systems.
\end{abstract}

KEY WORDS: Seascape · Metacommunity · Nursery grounds • Estuary • Barramundi • Predator-prey $\cdot$ Biotic interactions $\cdot$ Tidal wetland $\cdot$ Food availability $\cdot$ Food web Resale or republication not permitted without written consent of the publisher

\section{INTRODUCTION}

Fish distributions and connectivities across patches of habitat (e.g. stream reaches, pools, lakes, seagrass patches, mangrove stands) embedded in wetland landscapes (e.g. river basins, floodplains, saltmarshes, sandy substrate) are often analysed in a metapopulation framework - recognising that populations within patches are not closed, but linked by dispersal. Metapopulation approaches examine the interplay of local patch processes (such as fish preference for local environmental conditions) and regional landscape processes (such as movement among patches) in structuring populations across wetland systems. This multi-scale perspective improves our understanding of connectivity criteria necessary to sustain species' populations, and highlights patches of key conservation value (Hanski \& Thomas 1994, 
Hanski 1999), providing essential knowledge in the face of accelerated rates of landscape fragmentation (Morita \& Yamamoto 2002, Valentine-Rose et al. 2007). However, metapopulation approaches do not explicitly consider the influence of biological interactions, which can be important in structuring fish distributions across a landscape (Tonn 1990, Snodgrass et al. 1996, Tejerina-Garro et al. 1998).

Emerging 'metacommunity' approaches have begun to incorporate species interactions into metapopulation models to better represent processes driving organism distributions (Cottenie et al. 2003, Leibold et al. 2004). In these models, biological interactions are perceived as local-scale processes that modify communities within patches (Shurin 2001, Cottenie et al. 2003, Brown et al. 2011, Warfe et al. 2013). However, classic theories predicting species' distributions (e.g. ideal free distribution, optimal foraging theory) suggest that interactions among species, particularly predator-prey relationships, will also influence patch selection by an individual. Consequently, if inter-patch hydrological connectivity is sufficient to allow species to redistribute based on abiotic and biotic preferences (Leibold et al. 2004, Grober-Dunsmore et al. 2009), then prey availability is likely to be a key determinant of fish distribution patterns.

Most species of fish feed primarily on benthic or zooplanktonic invertebrates (Parrish 1989, Vadeboncoeur et al. 2002, Zagars et al. 2013). However, very few studies have explored the relationship between the spatial dynamics of fish and invertebrate prey at the scale of a wetland system, in either freshwater or marine settings (Grober-Dunsmore et al. 2009). Studies that have observed parallel dynamics of fish and invertebrates in freshwater systems have generally been confounded by scale, linking distributions across broad spatial scales (e.g. among separate river systems, drainage networks, or distant lakes) that far exceed fish dispersal capabilities (Tonn 1990, Heino 2002, Beisner et al. 2006, De Bie et al. 2012), and provide limited opportunity to identify patch selection processes. On the other hand, in open estuary and coastal seascape systems, oscillating priorities for feeding and refuge drive frequent tidal movements between patches and habitat types. Therefore, feeding grounds may only constitute a small proportion of a fish's home range (Pittman \& McAlpine 2003, Sheaves 2009), making it difficult to isolate and quantify the structuring influence of prey availability (Grober-Dunsmore et al. 2009).

Networks of pools scattered across tropical saltmarshes (henceforth referred to as 'tidal pools') how- ever, provide a tractable system where the balance between hydrological connectivity and discreteness of patches is ideal for examining bottom-up control influences. Tidal pools exist as an array of semienclosed study units, where predator and prey distributions can be representatively sampled and reliably compared. Relatively frequent tidal connections to the estuary channel and among pools (generally connecting during most daily tidal cycles) provide the potential for faunal populations to access each pool, and facilitate redistribution relative to preferred conditions (Davis et al. 2014). Moreover, samples of community structure from different years can be considered independent, as pool fauna is annually reset by 2 main processes: (1) ontogenetic migrations of fish from the salt-marsh system results in residence times of $<1 \mathrm{yr}$ (Davis et al. 2012), and (2) periodic wet season floods flush many species of fish (Davis et al. 2012) and benthic invertebrates (J. Sheaves pers. comm.) from the system. Independent replication is a feature lacking in previous empirical studies of metacommunity dynamics (Logue et al. 2011), but is key to identifying repeatable patterns and deterministic processes.

To examine the influence of predator-prey interactions on fish assemblage structure and patterns of realised connectivity across a wetland system, we compared the parallel distributions of fish, benthic invertebrates, and zooplankton across 13 tidal pools scattered across a North Queensland salt-marsh. If prey availability exerts considerable control over fish distribution, we expected to find spatial concordances between benthivorous fish and benthic invertebrates, and planktivorous fish and zooplankton taxa, respectively. The study was conducted over 2 annual cycles during the pre-wet season month of October, to allow invertebrate communities maximum time to recolonise following freshwater flushing.

\section{MATERIALS AND METHODS}

\section{Study site}

The study was conducted in Annandale Wetland $\left(19.19^{\circ} \mathrm{S}, 146.44^{\circ} \mathrm{E}\right)$, a $0.4 \mathrm{~km}^{2}$ Sporobolous virginicus salt-marsh system $8 \mathrm{~km}$ upstream of the Ross River mouth in Townsville, Queensland, Australia (Fig. 1). Interspersed across the wetland are 22 discrete permanent pools, ranging in area from $80 \mathrm{~m}^{2}$ to $2500 \mathrm{~m}^{2}$, and in low-tide depth from $30 \mathrm{~cm}$ to $130 \mathrm{~cm}$. The pools are mostly unvegetated and generally lack permanent woody debris. Substrates in pools vary from sand to fine mud. 


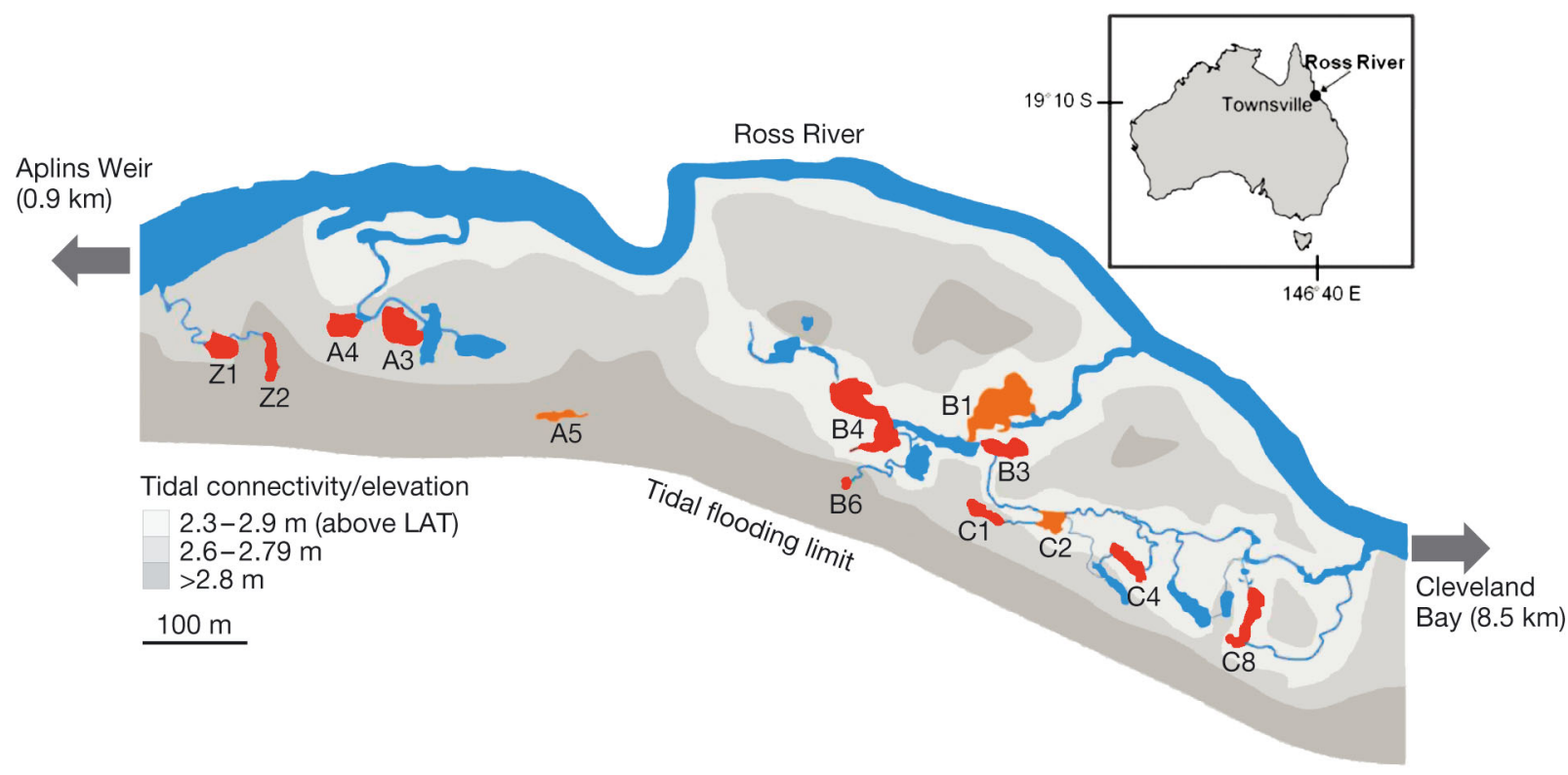

Fig. 1. Annandale Wetland containing the 22 wetland pools adjacent to the Ross River, Australia. Pools can be loosely decomposed into 4 groups (Z, A, B, C), based on the topographic basins they are set within, and the different arterial channels that connect groups of pools to the Ross River. Pools which were sampled in both 2010 and 2011 are shaded in red, whilst those sampled only in 2011 are shaded orange. The sampled pools were assigned unique alpha-numeric codes to discern between them in analyses. The wetland extends from the subtidal channel of the Ross River, south to the uppermost tidal limits (highest astronomical tide $\approx 4 \mathrm{~m}$ ). Different shades of grey illustrate the range of tidal heights at which different areas of the wetland are tidally inundated, and pools within them connected. This is essentially a function of elevation differences. Flooding patterns were determined by the deployment of a series of pressure loggers, the data from which were cross-referenced against parallel realised tide data (courtesy of the Townsville Port Authority). LAT: lowest astronomical tide

For much of the year, these pools exist as an array of semi-isolated wetland units tidally connected to each other and the Ross River. However, during wetseason months (January to March) Aplin's Weir (located $\sim 0.9 \mathrm{~km}$ upstream) overflows, blanketing the wetland in freshwater. These floods prompt extensive faunal shifts, resetting fish assemblages (Davis et al. 2012, 2014), exterminating the majority of benthic invertebrate taxa (J. Sheaves pers. comm.) and flushing zooplankton from the system (Kay 2009). Following floods, re-colonisation of pools primarily relies on tidal connections to the Ross River (which acts as a regional source of colonists), while subsequent exchange of individuals among pools are also likely to modify pool fauna.

Pools tidally connect to the Ross River (and each other) to varying extents, possibly modifying the potential for faunal colonisation. The level (frequency, duration, and depth) of tidal connectivity is primarily governed by the position of a pool along an elevation gradient from the estuary channel to the aquatic-terrestrial ecotone, but is modified by topographic heterogeneity within this gradient, as well as the presence of connecting channels. The majority of pools connect through most daily tidal cycles via narrow channels of varying length and depth. However, pools at higher elevations may only connect for a few days a month, some relying on connections over the tidally inundated saltmarsh surface (e.g. Pool A5; see Fig. 1). Based on these complex features, various descriptors of hydrological and structural connectivity can be derived relative to the level of tidal connection, connection distances, and the configuration of pools (Table 1). These different facets of connectivity may variously affect distributions of the different faunal groups.

\section{Data collection}

Benthic invertebrate, zooplankton, and fish densities (measured as catch-per-unit effort [CPUE]) were sampled in October 2010 in a subset of 10 pools encompassing a representative cross-section of connectivities, and again in October 2011 with the addition of 3 more pools to boost the sample size and strengthen analyses. Pre-wet season sampling ensured that invertebrate taxa had the maximum opportunity to re-establish on the wetland following the deleterious impacts of wet season floods (J. Sheaves pers. comm.). Pools were sampled at the bottom quarter of the tidal cycle (i.e. around low tide) during the new moon period. 
Table 1. Environmental variables used in the BIO-ENV and classification and regression tree (CART) procedures, to test for correlation with benthic invertebrate, fish, and zooplankton distribution data

\begin{tabular}{|c|c|c|c|}
\hline Variable & Description & Unit & Method \\
\hline \multicolumn{4}{|c|}{ Physico-chemical } \\
\hline Salinity & - & ppt & Portable refractometer \\
\hline Temperature & - & ${ }^{\circ} \mathrm{C}$ & Thermometer \\
\hline Visibility & - & $\mathrm{cm}$ & Secchi disc \\
\hline \multicolumn{4}{|c|}{ Pool morphology } \\
\hline $\begin{array}{l}\text { Substrate } \\
\text { class }\end{array}$ & Dominant substrate type/s & $\begin{array}{l}\text { Ranked: (1) silt, } \\
\text { (2) mud, (3) mud/sand, } \\
\text { (4) sand, (5) rubble }\end{array}$ & Visual survey \\
\hline $\begin{array}{l}\text { Maximum } \\
\text { depth }\end{array}$ & $\begin{array}{l}\text { Low tide maximum depth } \\
\text { of a pool }\end{array}$ & $\mathrm{cm}$ & Measuring staff \\
\hline Surface area & Low tide surface area of a pool & $\mathrm{m}^{2}$ & GIS \\
\hline \multicolumn{4}{|l|}{ Connectivity } \\
\hline $\begin{array}{l}\text { Critical tidal } \\
\text { connection } \\
\text { (CTC) }\end{array}$ & $\begin{array}{l}\text { Minimum tidal height required } \\
\text { for a pool to receive aquatic } \\
\text { connection to the Ross River }\end{array}$ & $\begin{array}{l}\mathrm{cm} \text { above lowest } \\
\text { astronomical tide } \\
\text { (LAT) }\end{array}$ & $\begin{array}{l}\text { Pool depths were continuously logged over a } \\
\text { tidal sequence. Depth fluctuations were } \\
\text { plotted against realised tide data (courtesy } \\
\text { of Townsville Port Authority). The lowest high } \\
\text { tide peak at which pool depth rose was taken } \\
\text { as the critical tidal connection, accounting for } \\
\text { lag between time of realised tide peak and } \\
\text { time of high water in Annandale Wetland }\end{array}$ \\
\hline $\begin{array}{l}\text { Channel } \\
\text { distance } \\
\text { (CD) }\end{array}$ & $\begin{array}{l}\text { Shortest path from Ross River to a } \\
\text { pool via channelised connections. } \\
\text { Channels were defined as water } \\
\text { courses connecting pools to the Ross } \\
\text { River or other pools. For } 2 \text { pools, } \\
\text { this included water courses running } \\
\text { over vegetated salt-marsh }\end{array}$ & $\mathrm{m}$ & GIS \\
\hline $\begin{array}{l}\text { Tidal overbank } \\
\text { distance } \\
\text { (TOD) }\end{array}$ & $\begin{array}{l}\text { Shortest path from Ross River to a } \\
\text { pool through tidally inundated } \\
\text { salt-marsh surface }\end{array}$ & $\mathrm{m}$ & GIS + ground truthing \\
\hline $\begin{array}{l}\text { Pool order } \\
\text { (PO) }\end{array}$ & $\begin{array}{l}\text { The number of intermediate pools } \\
\text { separating a pool from the Ross } \\
\text { River }\end{array}$ & number of pools & GIS \\
\hline $\begin{array}{l}\text { Nearest } \\
\text { neighbour } \\
(\mathrm{NN})\end{array}$ & $\begin{array}{l}\text { Distance to nearest pool via } \\
\text { channel or over tidally inundated } \\
\text { salt-marsh surface }\end{array}$ & $\mathrm{m}$ & GIS \\
\hline
\end{tabular}

Fish sampling

Fish were sampled using a beach seine net $(12 \mathrm{~m}$ long $\times 2 \mathrm{~m}$ deep, $6 \mathrm{~mm}$ mesh), with an effective sampling width of $8 \mathrm{~m}$. For each sample, the net was dragged (with one person pulling each end) for approximately $15 \mathrm{~m}$ before being hauled onto the bank. Some pools could be comprehensively sampled in a single haul, while larger pools required up to 3 net hauls, providing a representation of fish fauna across the entire area of each pool. Fish were identified to the lowest possible taxonomic level onsite, enumerated and returned to the water alive, with the exception of the noxious pest Oreochromis mossambicus, which was euthanased on site in accordance with fisheries guidelines. To control for possible recaptures of the same individuals in pools requiring multiple hauls, for each taxon only the maximum count across the hauls was used to represent the density of a species in a pool.

\section{Benthic invertebrate and zooplankton sampling}

Benthic invertebrates and zooplankton were simultaneously sampled using a manual rope-pulled epibenthic sledge, based on Hessler \& Sanders' (1967) design $(50 \times 50 \mathrm{~cm}$ mouth opening with a $200 \mu \mathrm{m}$ mesh size). Three replicate $4 \mathrm{~m}$ long sledge trawls were taken at each pool, stratifying for pool areas or any variation in substrate type. When the sledge was positioned, care was taken to avoid dis- 
turbing the sampling area by the operator walking in an arc around the intended path of the sledge prior to commencing sledge towing. The content of the catch-box was preserved in $4 \%$ phosphate buffered formaldehyde for laboratory identification. Specimens were identified under microscope to the lowest practical taxonomic level and quantified. The density of a taxon in a pool was measured as the average count across the 3 trawls. Since the study focused on the structuring potential of invertebrates as a food source for fish, it was considered practical to resolve invertebrate taxa to levels identified as prey items in fish dietary studies. Dietary studies generally do not resolve invertebrate prey types beyond family level, and resort to order and class in some circumstances (Wilson \& Sheaves 2001, Baker \& Sheaves 2005).

\section{Data analysis}

Species which were present in $<25 \%$ of samples were excluded from analysis to remove undue influence of rare species, as multiple zeros in the data matrix can 'swamp' the analysis, presenting a danger of absences driving model outputs. Faunal CPUE data were $\log (x+1)$ transformed to down-weight the influence of very common species (allowing less common species some influence on analytical outcomes and reducing the influence of extreme observations) (Clarke 1993).

Patterns of distribution were initially analysed separately for each faunal group, and then compared across groups to assess the extent of concordance. Since samples from 2010 and 2011 were independent, distributions from each year were analysed separately, and then compared. This enabled assessment of the extent of consistency in distribution pattern, and by extension the level of determinism of observed trends.

Zooplankton consisted almost exclusively of the calanoid copepod Acartia sinjiensis, so distributions were analysed with univariate classification and regression trees (CARTs), using $\log (\mathrm{CPUE}+1)$ as the response variable, and pool codes (Fig. 1) as the explanatory variable. Univariate CARTs operate by successively splitting data into increasingly homogenous groups based on the specified explanatory variables, by minimising residual sums of squares within a group at each split (De'ath \& Fabricius 2000). This technique is a robust non-parametric means for analysing relationships where assumptions of conventional linear approaches may be compromised (Breiman et al. 1984). Selection of the final tree model (i.e. determining where to reliably stop splitting data) was conducted using 10-fold cross-validation, selecting the smallest tree within $1 \mathrm{SE}$ of the minimum cross-validation error. This is a standard protocol for selecting robust, biologically meaningful trees (Breiman et al. 1984, De'ath \& Fabricius 2000). To help explain zooplankton distribution patterns, the procedure was repeated, replacing pool codes with a suite of environmental variables (Table 1).

Benthic invertebrate and fish distributions were analysed using non-metric multidimensional scaling (nMDS) of $\log (\mathrm{CPUE}+1)$ data, based on Bray-Curtis dissimilarities. Information on the taxa most highly correlated with the configuration of pools in the nMDS was displayed by superimposing vectors indicating direction of increasing density onto the ordination biplot. The direction of these vectors was determined by regressing each taxon onto the nMDS space, and the vector length was scaled to reflect the strength of correlation ( $R$ value). Only species most highly correlated with the nMDS space $(R>0.6)$ were plotted.

Relationships between distributions of fish/benthic invertebrates and environmental variables were tested using the BIO-ENV procedure in PRIMER, which calculates the combination of environmental variables that best explains patterns in the biological data. BIO-ENV works by generating Euclidean dissimilarity matrices from various combinations of environmental variables, and identifying the subset which maximises Spearman's rank correlation with the biological Bray-Curtis dissimilarity matrix (Clarke \& Warwick 1994). For the fish analysis, zooplankton and benthic invertebrate densities were included as additional environmental variables to assess the extent to which fish assemblage structure could be explained by prey distribution. For both fish and benthic invertebrates, the combination of variables that best accounted for biological patterns were regressed onto the nMDS ordination space and plotted as vectors (in a similar way to the taxa vectors), to assess the strength and direction of relationship between these key environmental variables and distribution patterns.

Patterns of distribution were qualitatively compared across the 3 faunal groups to assess the degree of concordance in spatial pattern (i.e. whether fish distribution reflected benthic invertebrate and/or zooplankton distribution). Relationships between benthic invertebrate and fish distributions were fur- 
ther explored using the RELATE routine in PRIMER, which is essentially a MANTEL test that calculates the Spearman's rank correlation ( $\rho)$ between 2 similarity matrices (Clarke \& Warwick 1994). The drivers

a) 2010

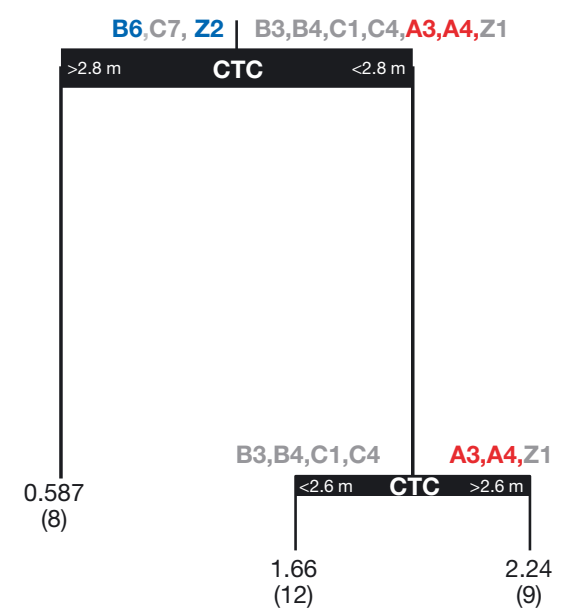

b) 2011

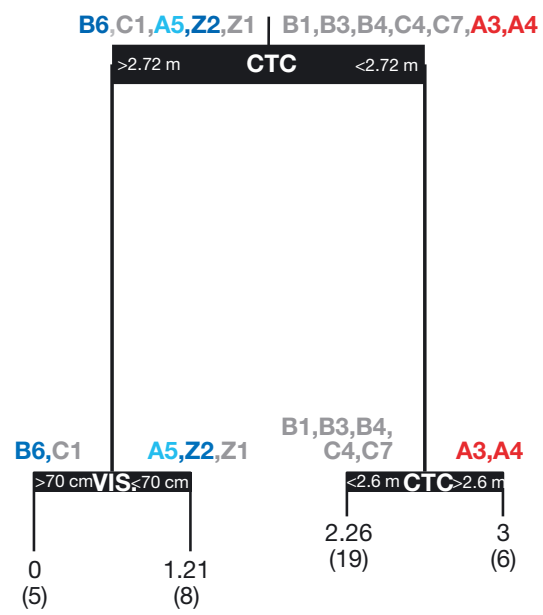

Fig. 2. Univariate classification and regression trees displaying the distribution of zooplankton (calanoid copepods) in (a) 2010 and (b) 2011, based on $\log ($ CPUE + 1) data. Mean catch-per-unit effort (CPUE) and sample sizes (in parentheses) are displayed at each terminal node. Pool groupings have been displayed either side of splits. Pools characterised by consistent high densities are coloured red, and those with consistently low abundances are coloured blue. The pale blue pool code (A5) represents a pool with low densities that was only sampled in 2011. The environmental variables that best explained these splits are indicated in black bars, along with the levels of these variables split in either direction. This information was obtained by re-running the analysis, replacing pool codes with the suite of environmental variables (Table 1). The structure of the tree output remained the same, suggesting that environmental variables successfully accounted for patterns. CTC: critical tidal connection; VIS.: visibility of concordances/disparities were then interpreted by examining the key environmental variables that explained distributions of each faunal group.

This combination of qualitative comparison of pattern and quantitative examination of environmental/ biological drivers was deemed the most effective and reliable means of assessing possible bottom-up control effects. Simply using BIO-ENV (or other techniques that correlate biological pattern with environmental variables and prey data) to explain fish assemblage structure may mask such effects; if all faunal groups co-vary relative to the same environmental variable, there is a danger that this variable may obscure meaningful relationships between faunal groups.

\section{RESULTS}

There were strong concordances in patterns of spatial distribution across the 3 faunal components (zooplankton, benthic invertebrates, and fish), that were consistent between the 2010 and 2011 samples. This was largely characterised by a binary split in faunal characteristics of pools that cut across all 3 taxonomic groups. In both years, Pool Z2 and B6 (and Pool A5, which was only sampled in 2011) had consistently

Table 2. Trophic function of abundant fish taxa in Annandale Wetland (b: benthivore; i: insectivore; zp: zooplanktivore; d: detritivore; $\mathrm{p}$ : piscivore; $\mathrm{h}$ : herbivore). These categorisations reflect the dominant food types of these species, derived from the best available information in the literature

\begin{tabular}{|c|c|c|}
\hline Taxon & $\begin{array}{l}\text { Trophic } \\
\text { group }\end{array}$ & Source \\
\hline Gerres filamentosus & $\mathrm{b} / \mathrm{i}$ & $\begin{array}{l}\text { Wilson \& Sheaves (2001), } \\
\text { Sheaves et al. (2006) }\end{array}$ \\
\hline Leiognathus equulus & $\mathrm{b} / \mathrm{zp}$ & $\begin{array}{l}\text { Staunton-Smith (2001), } \\
\text { Wilson \& Sheaves (2001), } \\
\text { Abrantes \& Sheaves (2009) }\end{array}$ \\
\hline Stolephorus spp. & $\mathrm{zp}$ & Hajisamae et al. (2003) \\
\hline Thryssa hamiltonii & $\mathrm{zp} / \mathrm{b}$ & Zagars et al. (2013) \\
\hline $\begin{array}{l}\text { Oreochromis } \\
\text { mossambicus }\end{array}$ & $\mathrm{d} / \mathrm{h} / \mathrm{p}$ & Doupé \& Knott (2010) \\
\hline Ambassis vachelli & zp & Zagars et al. (2013) \\
\hline Lates calcarifer & $\mathrm{p}$ & $\begin{array}{l}\text { Davis (1985), Sheaves } \\
\text { et al. (2006) }\end{array}$ \\
\hline Mugilid spp. & $\mathrm{d}$ & $\begin{array}{l}\text { Eggold \& Motta (1992), } \\
\text { Sheaves et al. (2006) }\end{array}$ \\
\hline Pseudomugil signifer & $\mathrm{i}$ & $\begin{array}{l}\text { Booth et al. (1985), Morton et } \\
\text { al. (1988), Platell \& Freewater } \\
\text { (2009), Pusey et al. (2004) }\end{array}$ \\
\hline Hypseleotris compressa & i & $\begin{array}{l}\text { Maddern et al. (2007), } \\
\text { Pusey et al. (2004) }\end{array}$ \\
\hline Selenotoca multifasciata & ta h & Lee et al. (1993) \\
\hline Megalops cyprinoides & $\mathrm{p} / \mathrm{i}$ & Coates (1987) \\
\hline
\end{tabular}



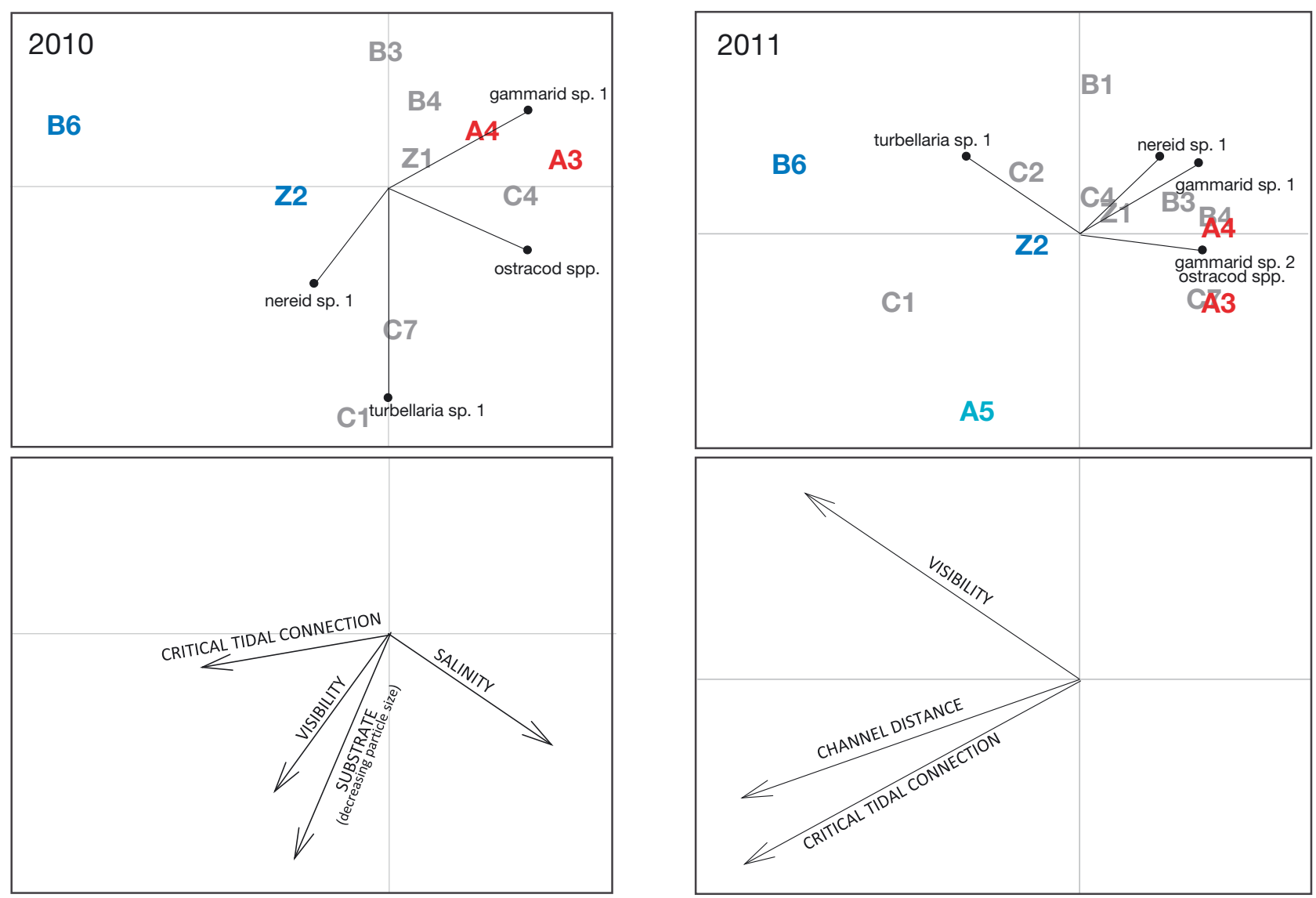

Fig. 3. Non-metric multidimensional scaling (nMDS) ordination, using Bray-Curtis dissimilarities on log(CPUE + 1) benthic invertebrate assemblage data in 2010 and 2011. Vectors radiating from the intersection of axes relate to taxa densities most highly correlated with the ordination space. Vectors indicate the direction of greatest increase in density, with length proportional to the strength of correlation with the ordination. Red pool codes indicate pools with consistently high densities of benthic invertebrates and blue pool codes indicate pools with consistently low densities of benthic invertebrates. The pale blue pool code (A5) represents a pool with low benthic invertebrate densities that was only sampled in 2011. The combination of environmental variables that best correlated with these data (as identified through the BIO-ENV procedure) are displayed as vectors regressed onto the MDS ordination space, shown on a separate complementary panel. These vectors can be interpreted in similar ways to these taxon vectors

lower densities of zooplankton (Fig. 2) and benthic invertebrate taxa (Fig. 3) than the majority of pools. These patterns were mirrored by distinct splits in fish assemblage structure (Fig. 4) (RELATE test between benthic invertebrate and fish nMDS ordinations: $\rho=$ 0.75 and 0.35 for 2010 and 2011, respectively). Pools Z2, B6, and A5 were characterised by greater densities of species that were predominantly detritivorous, herbivorous, and insectivorous (Table 2), including Hypseleotris compressa, Pseudomugil signifer, small juvenile mugilid spp., and small juvenile Selenotoca multifasciata (Fig. 4), while the rest of the pools were generally characterised by greater densities of species that were predominantly planktivorous and benthivorous, including Leiognathus equulus, Stolephorus spp., Herklotsichthys castelnaui, Gerres filamentosus, and Acanthopagrus spp.
BIO-ENV (for benthic invertebrates and fish) and CART (for zooplankton) analyses identified 'critical tidal connection' as the key environmental variable explaining this common axis of variability. Critical tidal connection explained the primary split in zooplankton distribution in both years, and also correlated with benthic invertebrate and fish distributions better than any other single variable (Table 3 ). Loading vectors on the benthic invertebrate and fish nMDS ordinations illustrate how 'critical tidal connection' strongly correlates with the split between Pools Z2, B6, and A5 and other pools on the wetland (Figs. $3 \& 4$ ). 'Critical tidal connection' refers to the minimum tidal height required to connect a pool to the Ross River, and is essentially a function of the position of a pool along an elevation gradient from the Ross River to the aquatic-terrestrial ecotone. 

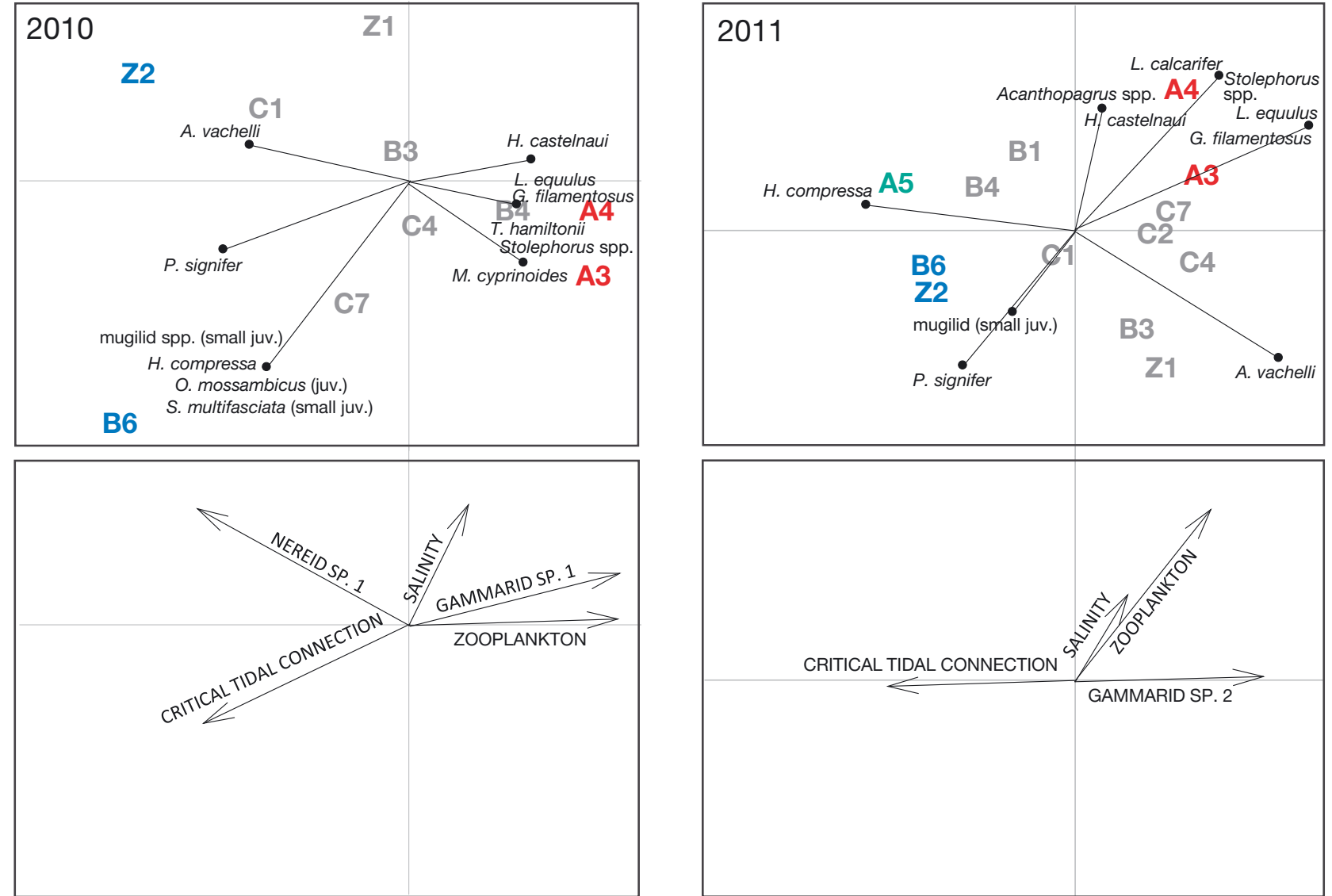

Fig. 4. Non-metric multidimensional scaling (nMDS) ordination, using Bray-Curtis dissimilarities on log(CPUE + 1) fish assemblage data in 2010 and 2011. See Fig. 3 for further explanation

Pools Z2, B6, and A5 are higher elevation pools connecting to the Ross River on tides $>2.8 \mathrm{~m}$, which represents medium to large spring high tides (Fig. 1). Meanwhile, other pools on the wetland are at lower elevations, connecting more regularly during medium to large neap high tides.

Concordances were not just limited to the higher elevation versus lower elevation split; among the lower elevation pools there were consistent productivity hotspots. Two pools (A3 \& A4) connecting to the Ross
River on larger neap tides (between $2.6 \mathrm{~m}$ and $2.7 \mathrm{~m}$ tides; i.e. at intermediate elevations on the wetland; Fig. 1), consistently harboured the greatest densities of zooplankton (Fig. 2). In the benthic invertebrate and fish ordination plots, these same pools were consistently grouped together opposite high-elevation pools (Figs. $3 \& 4$ ). This signifies that Pools A3 and A4 also had the highest densities of dominant benthic invertebrate taxa (gammarid amphipods and ostracods), and also benthivorous and planktivorous fish taxa

Table 3. Results of BIO-ENV analyses. The environmental variables that in combination best correlated with the biological data are marked with an ' $\mathbf{x}$ ', and the single most important variable in the correlation is marked ' $\mathbf{X}$ '. Spearman's rank correlation coefficients $(\rho)$ are given for the best combination and the single best variable. CTC: critical tidal connection; CD: channel distance; ZP: zooplankton. (-) Not examined

\begin{tabular}{|c|c|c|c|c|c|c|c|c|c|c|c|c|c|}
\hline Faunal group & Year & $\begin{array}{c}\text { Combination } \\
(\rho)\end{array}$ & $\begin{array}{c}\text { Single } \\
(\rho)\end{array}$ & CTC & Substrate & Salinity & Visibility & $\mathrm{CD}$ & $\mathrm{ZP}$ & $\begin{array}{l}\text { gamm. } \\
\text { sp. } 1\end{array}$ & $\begin{array}{l}\text { gamm. } \\
\text { sp. } 2\end{array}$ & $\begin{array}{c}\text { nereid } \\
\text { sp. } 1\end{array}$ & NOTE: Table \\
\hline Benthic invertebrates & $\begin{array}{l}2010 \\
2011\end{array}$ & $\begin{array}{l}0.61 \\
0.51\end{array}$ & $\begin{array}{l}0.43 \\
0.43\end{array}$ & $\begin{array}{l}\mathbf{X} \\
\mathbf{X}\end{array}$ & $\mathrm{x}$ & $\mathrm{x}$ & $\begin{array}{l}\mathrm{x} \\
\mathrm{x}\end{array}$ & $\mathrm{x}$ & - & - & - & - & $\begin{array}{l}\text { publication. } \\
\text { See Erratum }\end{array}$ \\
\hline Fish & $\begin{array}{l}2010 \\
2011\end{array}$ & $\begin{array}{l}0.83 \\
0.48\end{array}$ & $\begin{array}{l}0.73 \\
0.38\end{array}$ & $\begin{array}{l}\mathrm{x} \\
\mathbf{X}\end{array}$ & & $\begin{array}{l}\mathrm{x} \\
\mathrm{x}\end{array}$ & & & $\begin{array}{l}\mathrm{x} \\
\mathrm{x}\end{array}$ & $\mathbf{X}$ & $\mathrm{x}$ & $\mathrm{x}$ & \\
\hline
\end{tabular}


(Stolephorus spp., Herklotsichthys castelnaui, Leiognathus equulus, Gerres filamentosus, and Thryssa hamiltonii) (Table 2). Additionally, these 2 pools consistently harboured the highest densities of the piscivorous fish Lates calcarifer, and also the highest densities of the piscivore Megalops cyprinoides (Table 2) in 2010 (Fig. 4). Environmental loading vectors indicate that for benthic invertebrates, these patterns were consistently explained by low visibilities in Pools A3 and A4 (Fig. 3), whereas for fish these patterns were consistently explained by the high zooplankton and gammarid amphipod densities in these pools (Fig. 4).

\section{DISCUSSION}

We found consistent concordance in the distribution of zooplankton, benthic invertebrates, and fish across the wetland system. This was primarily characterised by a binary split in distribution pattern across all 3 groups that related to variations in the level of tidal connectivity. In both years, benthic invertebrates and zooplankton were more abundant in pools at lower elevations (which connect to the estuary channel on medium to large neap high tides), and less abundant in pools at higher elevations (which only connect on large spring high tides). These spatial patterns in invertebrate distribution were mirrored by distinct patterns in fish assemblage structure: lower elevation pools were characterised a

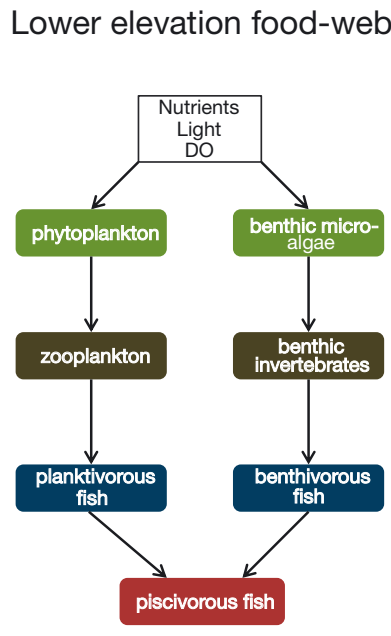

\section{b}

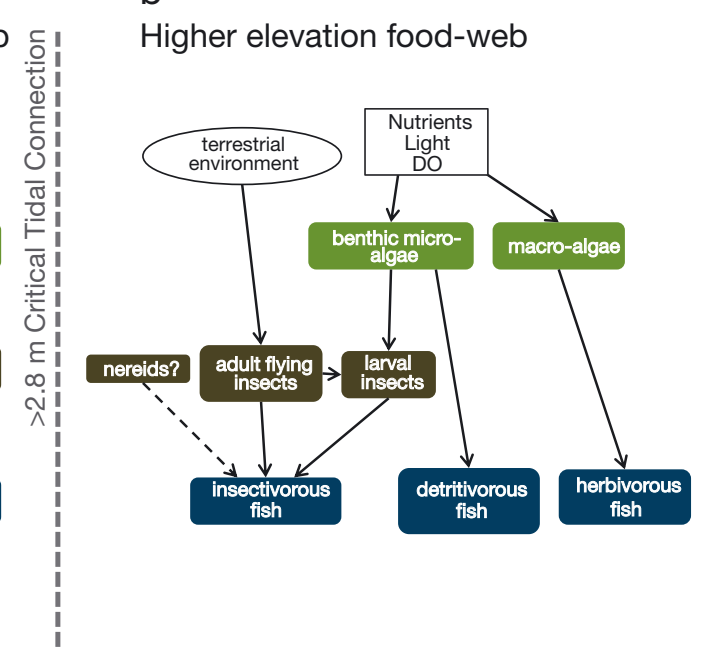

Fig. 5. Likely food-webs underpinning patterns of community assembly in (a) lower elevation pools and (b) higher elevation pools. While the majority of benthic invertebrate taxa were rare in higher elevation pools, nereid sp. 1 occurred in relatively high densities in higher elevation pools in 2010 (see Fig. 3). Nereids have therefore been included as a tentative component of the higher elevation food-web, which perhaps subsidise the diet of fish species that are predominantly insectivorous (e.g. Pseudomugil signifer) by greater densities of benthivorous and planktivorous fish (including Stolephorus spp., Herklotsichthys castelnaui, Leiognathus equulus, Gerres filamentosus, and Thryssa hamiltonii), whereas higher elevation pools were characterised by greater densities of fish species trophically decoupled from benthic invertebrates and zooplankton-instead comprising species that predominantly feed on detritus, insects, or algae (including Hypseleotris compressa, Pseudomugil signifer, Selenotoca multifasciata, mugilid spp., and Oreochromis mossambicus).

It is unclear whether these concordances reflect biological interactions among faunal groups or simply parallel responses to gradients of elevation/tidal connectivity. If the faunal groups are structured independently of one another, one would expect distribution patterns to vary among groups, due to vastly different life-history characteristics and dispersal modes (De Bie et al. 2012). However, concordances would still arise if each faunal group was constrained by a different mechanism relating to the elevation gradient. For instance, zooplankton and benthic invertebrates rely on passive transport via water flows to traverse the landscape, and may be limited by the lower frequency and duration of connection to higher elevation pools. Meanwhile, decreasing depths of connection along the elevation gradient may limit the majority of fish species (including benthivores and planktivores) to lower elevation pools (Thomas \& Connolly 2001, Bretsch \& Allen 2006, Hohausová et al. 2010). Perhaps only a limited number of fish species are capable of accessing the higher elevation pools, and these species demonstrate adaptations to subsist on the alternative food sources there (i.e. detritus, insects, and algae) (Fig. 5b). However, the possibility remains that benthivores and planktivores are also physically capable of accessing the higher elevation pools, but choose to remain in pools at lower elevations due to higher prey availabilities. This hypothesis could be tested through the manipulation of prey populations in pools at various elevations.

Among the lower elevation pools, there was another layer of concordance that provided more convincing evidence of bottom-up control effects. Two pools with particularly high densities of benthic invertebrates and zooplankton consistently harboured the 
greatest densities of benthivorous and planktivorous fish, and also the highest densities of common wetland piscivores Lates calcarifer and Megalops cyprinoides. This seems to represent a chain of bottom-up assembly spanning 3 trophic levels (primary consumer-secondary consumer-tertiary consumer). We can likely extrapolate beyond this to infer that primary productivity in the form of phytoplankton and benthic micro-algae was greatest in these pools (Fig. 5a), stimulating the settlement and propagation of benthic invertebrates and zooplankton, and in turn attracting secondary and tertiary consumers. The frequent tidal connectivity among lower elevation pools, and between lower elevation pools and the estuary channel, would seem to underpin this process by facilitating regular re-distribution of fish relative to preferred conditions and resource requirements.

Similar bottom-up control processes are also likely to influence patterns of movement and distribution across more open parts of the estuary and coastal seascape. For instance, McIvor \& Odum (1988) suggested that salt-marsh fish preferentially use shallow depositional banks at low tide rather than steep erosional banks, due to higher availabilities of benthic invertebrates. Additionally, there is evidence that in some instances bottom-up control processes may override habitat preferences in coastal systems. For example, King George whiting Sillaginodes punctata in South Australia are typically associated with seagrass beds during early juvenile stages (Bell \& Pollard 1989), but at some sites are more abundant over adjacent bare substrates where there are higher densities of meiofaunal food sources (Connolly 1994, Jenkins et al. 1997). Similarly, while Atlantic cod Gadus morhua are typically confined to waters of 0 to $5^{\circ} \mathrm{C}$, during periods of high prey (capelin Mallotus villosus) abundances, they move outside this temperature range to frequent areas where prey are aggegated (Rose \& Leggett 1989).

This complexity means that attempting to understand fish distributions based on correlations with landscape structure and physical habitat characteristics alone is unlikely to be successful (Harris \& Heathwaite 2012). Biological interactions could obscure or even decouple such species-environment relationships, generating substantial noise. Moreover, by failing to consider prey distribution there is a danger of attributing patterns to irrelevant mechanisms, based on spurious correlations with factors that may co-vary with prey availability. For instance, where distributions of fish across coastal landscapes may have previously been attributed to species- specific dispersal capabilities and habitat preferences, it is possible that fish may have actually been indirectly responding to the influence of these factors on their prey sources.

This study also demonstrates how biological interactions are a key component of metapopulation and metacommunity processes. Hydrological and structural connectivity among patches will only result in meaningful realised connectivity (i.e. fish dispersal and colonisation) if both biotic and abiotic conditions are suitable in the destination patch. For instance, in the present study it is likely that fish made forays into pools during high-tide connections, but did not remain as biological conditions (prey availabilities) were not suitable to sustain them. Equally, in some circumstances fish may avoid patches with high predator densities (Sogard \& Olla 1993, Jordan et al. 1997), or patchy distribution of predators may impose asymmetric mortality rates over the landscape (Townsend \& Crowl 1991, Rodriguez \& Lewis 1997). However, without information on spatio-temporal distribution across trophic levels, such mechanisms cannot be interpreted.

It is clear that spatial ecology studies in coastal and freshwater systems would greatly benefit from conceptualising fish distribution and connectivity within an ecosystem framework, explicitly recognising how different trophic levels may interactively affect each other's distribution. However, incorporating this information into empirical studies is likely to be arduous and require integration of knowledge across disciplines, including input from spatial, food-web, fisheries, and invertebrate ecologists.

Acknowledgements. We thank R. Baker and R. Johnston for offering their considered advice and critiques on this work, and E. Boogaerts, M. Malerba, M. Jankowski, and T. Mattone for their assistance in the field. We also thank Townsville Port Authority for the provision of realised tide data. This work was conducted as part of a $\mathrm{PhD}$ project funded by an International Postgraduate Research Scholarship awarded to B.D. by James Cook University.

\section{LITERATURE CITED}

Abrantes K, Sheaves M (2009) Food web structure in a nearpristine mangrove area of the Australian Wet Tropics. Estuar Coast Shelf Sci 82:597-607

$>$ Baker R, Sheaves M (2005) Redefining the piscivore assemblage of shallow estuarine nursery habitats. Mar Ecol Prog Ser 291:197-213

Beisner BE, Peres-Neto PR, Lindstrom ES, Barnett A, Longhi ML (2006) The role of environmental and spatial processes in structuring lake communities from bacteria to fish. Ecology 87:2985-2991

Bell JD, Pollard DA (1989) Biology of seagrasses: a treatise 
on the biology of seagrasses with special reference to the Australia region. In: Larkum AWD, McCoomb AJ, Shepherd SA (eds) Ecology of fish assemblages and fisheries associated with seagrassses. Elsevier, Amsterdam, p 565-609

Booth D, Pyke G, Lanzing W (1985) Prey detection by the blue-eye Pseudomugil signifer Kner (Atherinidae): analysis of field behaviour by controlled laboratory experiments. Mar Freshw Res 36:691-699

Breiman L, Friedman J, Olshen R, Stone C (1984) Classification and regression trees. Wadsworth International Group, Belmont, CA

Bretsch K, Allen D (2006) Tidal migrations of nekton in salt marsh intertidal creeks. Estuaries Coasts 29:474-486

Brown BL, Swan CM, Auerbach DA, Campbell Grant EH, Hitt NP, Maloney KO, Patrick C (2011) Metacommunity theory as a multispecies, multiscale framework for studying the influence of river network structure on riverine communities and ecosystems. J N Am Benthol Soc 30: $310-327$

> Clarke KR (1993) Non-parametric multivariate analyses of changes in community structure. Aust J Ecol 18:117-143

Clarke K, Warwick R (1994) Change in marine communities: an approach to statistical analysis and interpretation. Plymouth Marine Laboratory, Plymouth

Coates D (1987) Observations of the biology of tarpon, Megalops cyprinoides, in the Sepik River, Northern Papua New Guinea. Mar Freshw Res 38:529-535

Connolly RM (1994) The role of seagrass as preferred habitat for juvenile Sillaginodes punctata (cuv. \& val.) (Sillaginidae, Pisces): habitat selection or feeding? J Exp Mar Biol Ecol 180:39-47

> Cottenie K, Michels E, Nuytten N, De Meester L (2003) Zooplankton metacommunity structure: regional vs. local processes in highly interconnected ponds. Ecology 84: 991-1000

> Davis TLO (1985) The food of barramundi, Lates calcarifer (Bloch), in coastal and inland waters of Van Diemen Gulf and the Gulf of Carpentaria, Australia. J Fish Biol 26: 669-682

> Davis B, Johnston R, Baker R, Sheaves M (2012) Fish utilisation of wetland nurseries with complex hydrological connectivity. PLoS ONE 7:e49107

Davis B, Baker R, Sheaves M (2014) Seascape and metacommunity processes regulate fish assemblage structure in coastal wetlands. Mar Ecol Prog Ser 500:187-202

> De Bie T, De Meester L, Brendonck L, Martens K and others (2012) Body size and dispersal mode as key traits determining metacommunity structure of aquatic organisms. Ecol Lett 15:740-747

> De'ath G, Fabricius KE (2000) Classification and regression trees: a powerful yet simple technique for ecological data analysis. Ecology 81:3178-3192

Doupé RG, Knott MJ (2010) Rapid digestion of fish prey by the highly invasive 'detritivore' Oreochromis mossambicus. J Fish Biol 76:1019-1024

Eggold BT, Motta PJ (1992) Ontogenetic dietary shifts and morphological correlates in striped mullet, Mugil cephalus. Environ Biol Fishes 34:139-158

Grober-Dunsmore R, Pittman S, Caldow C, Kendall M, Frazer T (2009) A landscape ecology approach for the study of ecological connectivity across tropical marine seascapes. In: Nagelkerken I (ed) Ecological connectivity among tropical coastal ecosystems. Springer, Heidelberg, p 493-530
Hajisamae S, Chou LM, Ibrahim S (2003) Feeding habits and trophic organization of the fish community in shallow waters of an impacted tropical habitat. Estuar Coast Shelf Sci 58:89-98

Hanski I (1999) Metapopulation ecology. Oxford University Press, Oxford

> Hanski I, Thomas CD (1994) Metapopulation dynamics and conservation: a spatially explicit model applied to butterflies. Biol Conserv 68:167-180

> Harris GP, Heathwaite AL (2012) Why is achieving good ecological outcomes in rivers so difficult? Freshw Biol 57: 91-107

Heino J (2002) Concordance of species richness patterns among multiple freshwater taxa: a regional perspective. Biodivers Conserv 11:137-147

Hessler RR, Sanders HL (1967) Faunal diversity in the deepsea. Deep-Sea Res Oceanogr Abstr 14:65-78

Hohausová E, Lavoy RJ, Allen MS (2010) Fish dispersal in a seasonal wetland: influence of anthropogenic structures. Mar Freshw Res 61:682-694

Jenkins GP, May HMA, Wheatley MJ, Holloway MG (1997) Comparison of fish assemblages associated with seagrass and adjacent unvegetated habitats of Port Phillip Bay and Corner Inlet, Victoria, Australia, with emphasis on commercial species. Estuar Coast Shelf Sci 44:569-588

Jordan F, Bartolini M, Nelson C, Patterson PE, Soulen HL (1997) Risk of predation affects habitat selection by the pinfish Lagodon rhomboides (Linnaeus). J Exp Mar Biol Ecol 208:45-56

Kay JL (2009) The spatio-temporal dynamics of zooplankton assemblage in littoral wetland pools, of a tropical estuary, following freshwater flooding. Honours dissertation, James Cook University, Townsville

Lee CL, Peerzada N, Guinea M (1993) Control of aquatic plants in aquaculture using silver scat, Selenotoca multifasciata. J Appl Aquacult 2:77-84

Leibold MA, Holyoak M, Mouquet N, Amarasekare P and others (2004) The metacommunity concept: a framework for multi-scale community ecology. Ecol Lett 7:601-613

> Logue JB, Mouquet N, Peter H, Hillebrand H (2011) Empirical approaches to metacommunities: a review and comparison with theory. Trends Ecol Evol 26:482-491

Maddern MG, Morgan DL, Gill HS (2007) Distribution, diet and potential ecological impacts of the introduced Mozambique mouthbrooder Oreochromis mossambicus Peters (Pisces: Cichlidae) in Western Australia. J R Soc West Aust 90:203-214

- McIvor CC, Odum WE (1988) Food, predation risk, and microhabitat selection in a marsh fish assemblage. Ecology 69:1341-1351

Morita K, Yamamoto S (2002) Effects of habitat fragmentation by damming on the persistence of stream-dwelling charr populations. Conserv Biol 16:1318-1323

Morton R, Beumer J, Pollock B (1988) Fishes of a subtropical Australian saltmarsh and their predation upon mosquitoes. Environ Biol Fishes 21:185-194

Parrish JD (1989) Fish communities of interacting shallowwater habitats in tropical oceanic regions. Mar Ecol Prog Ser 58:143-160

Pittman SJ, McAlpine CA (2003) Movements of marine fish and decapod crustaceans: process, theory and application. Adv Mar Biol 44:205-294

Platell ME, Freewater P (2009) Importance of saltmarsh to fish species of a large south-eastern Australian estuary during a spring tide cycle. Mar Freshw Res 60:936-941 
Pusey B, Kennard M, Arthington A (2004) Freshwater fishes of north-eastern Australia. CSIRO Publishing, Collingwood

Rodriguez MA, Lewis WM (1997) Structure of fish assemblages along environmental gradients in floodplain lakes of the Orinoco River. Ecol Monogr 67:109-128

Rose GA, Leggett WC (1989) Interactive effects of geophysically-forced sea temperatures and prey abundance on mesoscale coastal distributions of a marine predator, Atlantic cod (Gadus morhua). Can J Fish Aquat Sci 46: 1904-1913

Sheaves M (2009) Consequences of ecological connectivity: the coastal ecosystem mosaic. Mar Ecol Prog Ser 391: $107-115$

Sheaves M, Collins J, Houston W, Dale P, Revill A, Johnston $\mathrm{R}$, Abrantes K (2006) The contribution of floodplain wetland pools to the ecological functioning of the Fitzroy River estuary. Cooperative Research Center for Coastal Zone, Estuarine and Waterway Management, Indooroopilly

Shurin JB (2001) Interactive effects of predation and dispersal on zooplankton communities. Ecology 82:3404-3416

Snodgrass JW, Bryan AL, Lide RF, Smith GM (1996) Factors influencing the occurrence and structure of fish assemblages in isolated wetlands of the upper coastal plain. Can J Fish Aquat Sci 53:443-454

Sogard S, Olla B (1993) The influence of predator presence on utilization of artificial seagrass habitats by juvenile walleye pollock, Theragra chalcogramma. Environ Biol Fishes 37:57-65

Staunton-Smith J (2001) The biology and ecology of ponyfish (Leiognathidae) in the Gulf of Carpentaria, Northern Australia. PhD dissertation, University of Queensland, Brisbane

Editorial responsibility: Janet Ley, St. Petersburg, Florida, USA
Tejerina-Garro FL, Fortin R, Rodríguez MA (1998) Fish community structure in relation to environmental variation in floodplain lakes of the Araguaia River, Amazon Basin. Environ Biol Fishes 51:399-410

Thomas BE, Connolly RM (2001) Fish use of subtropical saltmarshes in Queensland, Australia: relationships with vegetation, water depth and distance onto the marsh. Mar Ecol Prog Ser 209:275-288

$>$ Tonn WM (1990) Climate change and fish communities: a conceptual framework. Trans Am Fish Soc 119:337-352

Townsend CR, Crowl TA (1991) Fragmented population structure in a native New Zealand fish: an effect of introduced brown trout? Oikos 61:347-354

> Vadeboncoeur Y, Vander Zanden MJ, Lodge DM (2002) Putting the lake back together: reintegrating benthic pathways into lake food web models. Bioscience 52:44-54

Valentine-Rose L, Layman CA, Arrington DA, Rypel AL (2007) Habitat fragmentation decreases fish secondary production in Bahamian tidal creeks. Bull Mar Sci 80: 863-877

Warfe DM, Pettit NE, Magierowski RH, Pusey BJ, Davies PM, Douglas MM, Bunn SE (2013) Hydrological connectivity structures concordant plant and animal assemblages according to niche rather than dispersal processes. Freshw Biol 58:292-305

Wilson J, Sheaves M (2001) Short-term temporal variations in taxonomic composition and trophic structure of a tropical estuarine fish assemblage. Mar Biol 139: 787-796

Zagars M, Ikejima K, Kasai A, Arai N, Tongnunui P (2013) Trophic characteristics of a mangrove fish community in southwest Thailand: important mangrove contribution and intraspecies feeding variability. Estuar Coast Shelf Sci 119:145-152

Submitted: June 19, 2013; Accepted: November 27, 2013 Proofs received from author(s): February 16, 2014 